\title{
The Mediterranean diet for Polish infants: a losing struggle or a battle still worth fighting?
}

\author{
Kamil Konrad Hozyasz • Barbara Radomyska • \\ Karolina Kot
}

Received: 26 May 2010/Accepted: 23 August 2010/Published online: 18 September 2010

(C) The Author(s) 2010. This article is published with open access at Springerlink.com

\begin{abstract}
The Mediterranean diet is well known for its health-promoting effects. Among its key ingredients, olive oil is the most characteristic. Processing industries have been successfully manufacturing and marketing jarred baby foods with the use of vegetable oils, including olive oil, as well as other sources of visible fat. We aimed to survey manufacturer claims concerning added fat in jarred infant foods supplied to the Polish market. A total of 124 kinds of infant foods from six suppliers were analyzed. Corn, canola, and soybean oil occupied the first three positions, respectively, in rank order of vegetable oils used in jarred baby foods. In our sample, only one type of readyto-eat jars with vegetables contained olive oil. $11 \%$ of products contained cow milk butter or cream. $61 \%$ of jarred "dinners" contained poultry or fish, which are typical sources of animal protein in the Mediterranean diet. Given that commercial baby foods currently available in the Polish market contain no olive oil, we advocate considering home preparation of infant foods with the use of visible fat. Medical professionals should encourage food manufacturers to return to the concepts of the Mediterranean diet for young consumers, aimed at long-term health.
\end{abstract}

Keywords Olive oil - Commercial baby food . Homemade food · Dietary patterns .

Optimal feeding practices

K. K. Hozyasz ( $\square)$

Institute of Mother and Child, Warsaw, Poland

e-mail: khozyasz@verco.com.pl; kamil.hozyasz@imid.med.pl

B. Radomyska $\cdot$ K. Kot

Pediatric Department, Institute of Mother and Child,

Warsaw, Poland

\section{Introduction}

During the weaning period and transition to solid foods in the first year of life, infants take a critical step in their eating behavior and need to meet high nutrient requirements [1, 2]. They are exposed to new foods and food combinations, which should ensure a smooth transition to the family diet later in life. At this stage, either homemade or commercially prepared foods may be fed. It is worth noting that in prosperous countries the modern diet differs considerably from that of previous generations, now dominated by products that have been processed, stored, and transported over great distances. Traditional, coldpressed vegetable oils of the highest nutritional quality, e.g. extra virgin olive oil, may therefore constitute an important part of the modern diet [3, 4].

In Poland, many infants do not receive any traditional homemade foods and even fruits come from purchased jars. Commercial baby foods are regarded by some parents and medical professionals to be more appropriate for several reasons: they undergo intense screening for contaminants in comparison to foods sold for the general population, contain no additives of certain types, and are thought to be designed to help infants meet nutrient requirements [5]. The process of peeling, however, was identified as the most effective, and simple, procedure in reducing residues, e.g. pesticides, in fruits and vegetables [6]. Moreover, contrary to homemade food, which does not contain furan, the highest average content of this chemical was found in ready-to-eat baby foods with pasta meals, followed by vegetable meals and meals with meat [7]. Furan is considered to be potentially hazardous chemical and is classified as a possible carcinogen. The problem of this chemical in homemade food may only arise if meals with potatoes are stored and then hardly re-heated [7]. 
There is a growing body of evidence that flavor experiences and dietary patterns in childhood influence these patterns later in life $[1,8,9]$. It is most likely early in life that culture-specific flavor preferences are initiated [10, 11]. Consequently, exposure to flavors and smells of transitory foods may serve to heighten preferences for "known tastes" in the family diet later in adulthood. Moreover, adopting elements of childhood dinner patterns was recognized to be an important part of the social reproduction of family identities across generations [12].

Processing industries have been successful in manufacturing and marketing jarred baby foods on a commercial scale. Available products contain different ingredients and depend on the manufacturer, country, traditional cuisine, income rate, and lastly, personal beliefs and values of parents $[9,11]$. Jarred foods with vegetables, meats, and desserts may contain added fat from a variety of sources: vegetable oils, cow milk butter, or cream. Manufacturer advertising makes the majority of consumers feel safe, causing them to believe that they are doing the best possible in buying given products [11]. A noteworthy fact is that many types of baby foods produced by international manufacturers are, in essence, the same mixtures with different names; this procedure aims to exploit the specifics of local markets without delivering any new, real value [11].

In the book, How to Eat Well and Stay Well the Mediterranean Way by Keys [13] first used the term "good Mediterranean diet" to describe the eating patterns of populations dwelling in southern Europe, where the olive tree (Olea europaea) is an emblematic species [4, 14]. There is variation between the exact diet in different parts of the Mediterranean region. However, generalized and distinctive dietary patterns do exist, including olive oil as the main source of visible fat, employed both in cooking and as a dressing, moderate fish and poultry but low red meat consumption, high intake of vegetables, fruits, legumes, nuts, and whole-grain cereals [4, 14-16]. When dietary fats are added, in accordance with the traditional Mediterranean diet, olive oil is the choice for children [17]. It has been repeatedly observed that individuals applying the Mediterranean diet have reduced risks of type 2 diabetes and other diseases associated with the metabolic syndrome, autoimmunological diseases, and certain forms of cancer [18]. Moreover, considerable evidence exists that the Mediterranean diet increases quality of life in the course of ageing, as well as longevity [13, 19]. The health benefits of olive oil have been attributed to two main constituents: a high oleic acid (monounsaturated fatty acid, 18:1n-9) content (70-85\%) and a large amount of antioxidant compounds, which also possess antiviral, antibacterial, and immunomodulating effects $[3,4,14,16]$. Polyphenols found in virgin olive oil are linked to both its flavor and its remarkable stability [3].
The introduction of solid foods in infancy is one of the primary matters often discussed by parents with their child's pediatrician. However, many parents do not feel that the diet of their child may be linked to poor health outcomes in the future. Parents should be educated about the interplay of environmental and genetic influences on children, specifically during the early years of development when the child is maturing and taking control of its own diet [11]. Nutrition educators should increase the critical awareness of parents in relation to their child's solid food choices. It is important to emphasize to parents the fundamental role that the Mediterranean diet and consumption of foods with olive oil play in a healthy life style $[14,20]$. Parental management of the family food environment may be complicated by numerous mitigating factors, e.g. health literacy, time availability, and financial resources. Considering the role baby food manufacturers play in the infant's contextual environment, their products, as well as the manufacturers themselves, should also be viewed as key players and central agents in establishing dietary habits. Consequently, we attempted to survey manufacturer claims concerning added fat in jarred infant foods supplied to the Polish market.

\section{Methods}

Commercially jarred baby foods containing vegetable or animal fat, as an ingredient specified by producers, were chosen for the investigation. The products, offered for children aged 5-12 months were collected from six brands available on the Polish market in November 2009 (Gerber, Hipp, Nutricia, Hama, Rossmann-Babydream, and CarrefourBaby). A total of 124 jarred foods were classified by type: vegetables, mixed main dishes (so-called "dinners" containing vegetables and meat), and dessert-type foods.

\section{Results}

Of the jarred baby foods containing added fat supplied to the Polish market, a large proportion constituted so-called "dinners" (68\%) and mixtures of vegetables (19\%) whereas desserts were less significant (13\%) (Table 1). None of the manufacturers delivered precise data about the amounts of added fat. Only 11 (9\%) of the examined foods provided information regarding vegetable oil content, without specification of the source. More than one kind of fat was added to two different products. Only in one type of mixed vegetables did the manufacturer specify that olive oil was used (Table 2). The most frequently used fat, however, was corn oil (Table 2). The dinner-type foods contained either meat (chicken, turkey, pork, beef, veal, lamb, and rabbit) or fish 
Table 1 Declared sources of added fat in jars in relation to type of infant's solid food (vegetables, so called "dinners" and dessert-type foods)

\begin{tabular}{lllllllllll}
\hline Type of food & $\begin{array}{l}\text { Number } \\
\text { of brands }\end{array}$ & $\begin{array}{l}\text { Olive oil, } \\
n(\%)\end{array}$ & $\begin{array}{l}\text { Canola } \\
n(\%)\end{array}$ & $\begin{array}{l}\text { Soybean } \\
\text { oil, } n(\%)\end{array}$ & $\begin{array}{l}\text { Corn oil, } \\
n(\%)\end{array}$ & $\begin{array}{l}\text { Sunflower } \\
\text { oil, } n(\%)\end{array}$ & $\begin{array}{l}\text { Palm oil, } \\
n(\%)\end{array}$ & $\begin{array}{l}\text { Butter, } \\
n(\%)\end{array}$ & $\begin{array}{l}\text { Cream, } \\
n(\%)\end{array}$ & $\begin{array}{l}\text { Unspecified } \\
\text { vegetable oil, } n(\%)\end{array}$ \\
\hline Vegetables & $24^{\mathrm{b}}$ & $1(4.5)$ & $3(12.5)$ & $2(8.3)$ & $13(54.2)$ & 0 & 0 & $3(12.5)$ & $3(12.5)$ & $2(8.3)$ \\
"Dinners" & 84 & 0 & $24(28.6)$ & $12(14.3)$ & $28(33.3)$ & $7(8.3)$ & 0 & $9(10.7)$ & 0 & $4(4.7)$ \\
"Desserts" & 16 & 0 & 0 & 0 & $9(56.2)$ & $1(6.2)$ & $1(6.2)$ & 0 & 0 & $5(31.2)$ \\
\hline
\end{tabular}

${ }^{\text {a }}$ Low-erucic acid rapeseed oil

b There are two brands with more than one source of added fat [(1) canola + butter + cream; (2) corn oil + cream]

Table 2 Declared sources of added fat in jars with infant solid food in relation to manufacturers

\begin{tabular}{lllllllllll}
\hline Manufacturer & $\begin{array}{l}\text { Number } \\
\text { of brands }\end{array}$ & $\begin{array}{l}\text { Olive oil, } \\
n(\%)\end{array}$ & $\begin{array}{l}\text { Canola } \\
n(\%)\end{array}$ & $\begin{array}{l}\text { Soybean } \\
\text { oil, } n(\%)\end{array}$ & $\begin{array}{l}\text { Corn oil, } \\
n(\%)\end{array}$ & $\begin{array}{l}\text { Sunflower } \\
\text { oil, } n(\%)\end{array}$ & $\begin{array}{l}\text { Palm oil, } \\
n(\%)\end{array}$ & $\begin{array}{l}\text { Butter, } \\
n(\%)\end{array}$ & $\begin{array}{l}\text { Cream, } \\
n(\%)\end{array}$ & $\begin{array}{l}\text { Unspecified } \\
\text { vegetable oil, } n(\%)\end{array}$ \\
\hline A & 37 & 0 & $19(51.4)$ & 0 & $9(24.3)$ & 0 & 0 & $8(21.6)$ & $1(2.7)$ & 0 \\
B & 39 & 0 & $7(17.9)$ & $14(35.9)$ & $11(28.2)$ & $1(2.6)$ & 0 & $3(7.7)$ & 0 & $3(7.7)$ \\
C & $33^{\mathrm{b}}$ & 0 & $1(3.0)$ & 0 & $30(90.9)$ & 0 & 0 & $1(3.0)$ & $2(6.1)$ & $2(6.1)$ \\
D & 6 & 0 & 0 & 0 & 0 & 0 & 0 & 0 & 0 & $6(100)$ \\
E & 8 & 0 & 0 & 0 & 0 & $7(87.5)$ & $1(12.5)$ & 0 & 0 & 0 \\
F & 1 & $1(100)$ & 0 & 0 & 0 & 0 & 0 & 0 & 0 & 0 \\
Total & $124^{\mathrm{b}}$ & $1(0.8)$ & $27(21.8)$ & $14(11.3)$ & $50(40.3)$ & $8(6.5)$ & $1(0.8)$ & $12(9.7)$ & $3(2.4)$ & $11(8.9)$ \\
\hline
\end{tabular}

${ }^{\text {a }}$ Low-erucic acid rapeseed oil

b There are two brands with more than one source of added fat [(1) canola + butter + cream; (2) corn oil + cream]

(lax, cod) with different intramuscular fat contents. 51 of the $84(61 \%)$ types of dinners contained poultry or fish, which are typical ingredients of the Mediterranean diet. Cereal content was also varied among the examined 110 foods and included corn, wheat, rice, hordeum, and oats, which were added to four types of desserts.

\section{Discussion}

An increasing number of working mothers strongly influences the demand for ready-to-eat jars. This contrasts with a traditional diet comprising mostly of foods produced and marketed locally, and eaten shortly after harvesting. It is clear that early sensory experiences have an impact on the acceptance of food later in life. Mediterranean ingredients like extra virgin olive oil, fresh garlic and potted basil appear to be the most prominent taste markers in the dinner patterns of the Western middle class [12]. The use of olive oil provides volatile and non-volatile flavors that are reflected throughout the entire dish [3]. Moreover, it should be noted that using olive oil in the kitchen encourages the consumption of large amounts of vegetables and legumes, antioxidant and fiber-rich foods, without trans fatty acids, which many westernized consumers would otherwise find difficult to fit into their diet [14]. Polish infant feeding guidelines recommend the use of olive oil, low-erucic acid rapeseed oil (canola), and butter in the first year of life [21]. Unfortunately, in our study only one type of ready-to-eat jars contained olive oil. Corn oil, which is not advised in Polish infant guidelines, occupies the first position in rank order of visible fat used in jarred baby foods supplied to our market. Canola oil is ranked second in the list of oils added to ready-to-eat baby foods. Contrary to corn oil, canola is now held by some experts to be the best available edible oil [22]. Canola oil is lowest in saturated fat among vegetable oils and is more than twice as high in $\alpha$-tocopherol than soybean oil. Soybean oil, which is the dominant edible oil in the US, was used by only one manufacturer present on the Polish market. Sunflower oil is regarded by some experts as unsuitable for manufacturing shelf-stable foods because of its poor oxidative stability [23]; in our sample, it was found to be used by two producers. Palm oil, derived from palmitic acid esterified to sn-1 and sn-3 positions, increases fecal hardness due to lipid absorption and calcium salt formation, and is not advisable for young children [24]. In our study, one type of jarred dessert with fruits and biscuits was found to contain palm oil. Natural, semi-solid palm oil was reported to be beneficial for the aeration of fat-sugar mixtures [25]. 11\% food types contained cow milk butter or cream. Baby foods with butter or cream are more popular in Russia and France 
[11]. Greco et al. [17] made a noteworthy suggestion that Italian children aged 5-32 months seem to be losing some of the advantages of the Mediterranean diet as a result of the increasing use of processed, full-fat dairy products. However, current recommendations are to avoid the restriction of fat in children under the age of 2-3 years $[1,26]$. The role of dietary fat types as early determinants of childhood obesity has, as yet, been poorly studied [26]. As solid foods become a larger part of the daily regime, it is important that products chosen be linked to a beneficial, nutritious diet. It therefore seems reasonable to recommend foods containing olive oil, which help to promote good eating habits for the future.

Current recommendations for solid feeding of infants are based on relatively few facts and many opinions [1]. However, primary prevention of cardiovascular disease, which remains a major health problem in modern, westernized populations, should begin in children, as early vascular lesions already start to develop in the first years of life [20]. Olive oil consumption provides benefits for plasma lipid levels, oxidative stress, and is inversely associated with the reduction of systolic and diastolic blood pressure [4, 14]. These and other factors provide the basis for regarding the consumption of olive oil as the gold standard of a healthy diet for children. Allergies are becoming an increasing problem worldwide. The results of Chatzi et al. [27] and Kim et al. [28] studies suggest that adherence to the Mediterranean diet helps in the prevention of allergies in children. An anthroposophic, holistic lifestyle approach appears to lessen the risk of atopic diseases [29]. Children from families following an anthroposophic way of life consume mostly homemade food, olive oil, and oats. Interestingly, in Poland, as in other Central and North European countries, the oat has been regarded as one of the most healthy local crops for centuries, and is now of great nutritional interest because of its special composition and association with reductions in risk of cardiovascular disease, diabetes, and obesity [30]. An apparent association exists between the early introduction of oats into the child's diet and protection against asthma [31]. It is not yet clear to what extent oats influence the reduction of allergies and risk of cardiovascular diseases; they do, undoubtedly, play a certain role and are therefore a welcomed ingredient in commercial baby foods. It is noteworthy that the addition of oats can increase the satiating efficiency of the product [32]. In our sample, only $4 \%$ of the examined foods with grain ingredients contained oats.

Similarly, as in other European countries, a major part of the Polish baby food market is occupied by several multinationals-Gerber, Nutricia, Hipp, Rossmann-leaving very few opportunities for smaller companies [10]. Polish baby food manufacturers and distributors were rapidly privatized in post-Communist Poland as the country has become more affluent [33]. However, our country currently lacks the presence of pressure groups interested in controlling baby food profit-making firms, which are thought, by the majority of consumers, to restrict their profits in certain areas voluntarily [34]. Baby food manufacturers are spending millions of dollars to develop newer products but, ironically, technological data on baby food is limited [35]. We do not know the reasons why manufacturers do not use olive oil and why products supplied to the Polish markets are largely based on various types of vegetable oils, depending on the company (in some cases corn oil, in others soya or sunflower oil, etc.). The health of our children is one of the most important investments that we can make. Consistency between recognized nutritional standards, national nutrition goals and practice is regarded as an important goal of public health [36-38]. Guerra et al. [20] reported that Portuguese children aged 12-48 months have lower values of monounsaturated and n-3 polyunsaturated fatty acids in comparison to young Germans, and concluded that traditional food habits are disappearing, even in countries lining the Mediterranean basin. The Mediterranean diet is a practical and highly enjoyable dietary pattern [14]. Unfortunately, young people tend not to associate healthy foods found in the traditional Mediterranean cuisine with positive lifestyle images and "junk" foods increasingly crowd out nutritionally rich essentials [36]. We believe that what we are witnessing, at least in the case of Poland, is a public health crisis with regards to commercially supplied solid foods for infants. Our assessment, as stated similarly by other investigators [20], is that health care professionals should be responsible for encouraging manufacturers and distributors of foods to return to the concepts of a Mediterranean diet for young consumers, aimed at maintenance of longterm health.

If technical reasons are to be blamed for the lack of olive oil use by most manufacturers, a valuable alternative could be considering the production of a variant of jarred infant solid foods to which olive oil would be added by the consumers themselves, directly before serving. If, however, the high price of olive oil is the limiting factor for manufacturers in Poland, then companies could possibly look into diversifying their product supply, reflecting the demands of more conscientious consumers. The main olive oil producing countries have the highest annual consumption per capita-Greece $>20 \mathrm{~kg}$, Spain and Italy about $13 \mathrm{~kg}$. In Central Europe and the US, consumption is below $1 \mathrm{~kg} / \mathrm{capita} / \mathrm{year}$ [3]. The supply of olive oil is likely to be easily increased along with its growing demand, as there are good perspectives for the future expansion of olive oil production in many non-Mediterranean regions [39].

In some countries, it is a common practice to prepare meals for infants only partially based on processed foods. 
Baby foods found in Italy, for instance, included a significant proportion of jarred or lyophilisated (powdered) meats alone, whereas mixtures of meat and vegetables were rather uncommon [40]. Interestingly, there are two types of baby foods containing meat alone, available in the Polish market, that is recommended by the manufacturer for infants who completed 6 months. However, nearly $50 \%$ of their content is so-called meat separated mechanically (MSM) and for this reason, we do not feel that they should be consumed by very young children. Generally speaking, an Italian mother, raised herself on the tradition of Mediterranean cuisine and family dinners, feels proud if cooking for her infant [11]. In the Mediterranean region, the perspective of buying jarred baby food in a supermarket for many families seems ridiculous [11]. Parents who claim to feed their infants with only freshly cooked food, among the reasons for doing so list ensuring maximum nutritional quality and preserving vitamins, avoiding artificial additives, and the ability to set a basis for a good taste sense [11]. During processing and long-term storage, vitamin and antioxidant levels decrease [41]. Mothers' education is considered to directly influence how she feeds her child. Young infant gastrointestinal tract is usually unable to handle grossly chopped homemade solid foods, so such diet may exert an inhibitory effect on digestion and nutrients absorption. Caregivers should be aware of food preparing guidelines, e.g. the first solids must be carefully blended in order to increase their digestibility [42]. Digestibility profiles of commercial homogenized products are similar to or often better than those of the corresponding homemade foods [42]. However, another concern has been the association of delayed introduction (after the age of 9 months) of partially blended or lumpy foods and decreased consumption of fruits and vegetables in later life $[2,8]$.

There is also another point to consider regarding commercially prepared baby foods containing fat. Glass jars are commonly closed using a metal lid coated with a seal made of PVC including up to $50 \%$ plasticizers (most commonly epoxidized soybean oil), which comes in direct contact with the jarred food [40]. Parents should be educated that if the jars are stored upright it is more likely that migration of epoxidized oil may occur [40].

Humans have evolved an unusually flexible strategy for feeding infants and using special transitional foods. Sellen [38] suggested that this flexibility might have been adaptive in the different environments in which humans evolved, but it creates the potential for mismatches between optimal and actual feeding practices in many populations. We should keep in mind not only the shortterm effects but also consider long-term consequences of infant feeding practices. Finally, it is important to emphasize that the best-known diet of European origin, producing health-promoting effects is the Mediterranean diet; olive oil prevailing as its keystone. Given that currently commercial baby foods on the Polish market contain no olive oil, we endorse considering home preparation of infant foods with added visible fat.

\section{Key messages}

- Flavor experiences and dietary patterns in early childhood influence these models later in life.

- In the Mediterranean diet, olive oil is the main source of visible fat. Olive oil provides flavors that are present throughout the entire dish.

- Jarred commercial baby foods supplied to the Polish market contain no olive oil. Food manufacturers should be encouraged to return to the concepts of a Mediterranean diet for young consumers.

\section{Conflict of interest None.}

Open Access This article is distributed under the terms of the Creative Commons Attribution Noncommercial License which permits any noncommercial use, distribution, and reproduction in any medium, provided the original author(s) and source are credited.

\section{References}

1. Agostoni C, Decsi T, Fewtrell M et al (2008) Complementary feeding: a commentary by the ESPGHAN Committee on Nutrition. J Pediatr Gastroenterol Nutr 46:99-110

2. Coulthard H, Harris G, Emmett P (2009) Delayed introduction of lumpy foods to children during the complementary feeding period affects child's food acceptance and feeding at 7 years of age. Matern Child Nutr 5:75-81

3. Boskou D (2002) Olive Oil. In: Gunstone FD (ed) Vegetable oils in food technology. Blackwell Publishing, Oxford

4. Mataix J, Battino M, Ramirez-Tortosa MC et al (2008) Virgin olive oil: a key healthy component of the Mediterranean diet. Mediterr J Nutr Metab 1:69-75

5. Scanlan FP (2007) Potential contaminants in the food chain: identification, prevention and issue management. Nestle Nutr Workshop Ser Pediatr Program 60:65-78

6. Stepan R, Ticha J, Hajslova J et al (2005) Baby food production chain: pesticide residues in fresh apples and products. Food Addit Contam 22:1231-1242

7. Lachenmeier DW, Reusch H, Kuballa T (2009) Risk assessment of furan in commercially jarred baby foods, including insights into its occurrence and formation in freshly homecooked foods for infants and young children. Food Addit Contam 26:776-785

8. Northstone K, Emmet P, Nethersole F (2001) The effect of age of introduction to lumpy solids on foods eaten and reported feeding difficulties at 6 and 15 months. J Hum Nutr Diet 14:43-54

9. Maier A, Chabanet C, Schaal B et al (2007) Food-related sensory experience from birth through weaning: contrasted patterns in two nearby European regions. Appetite 49:429-440

10. Mennella JA (1997) The flavour world of infants: a cross-cultural perspective. Nutr Today 32:142-151 
11. Gritsai O (2001) Haute cuisine versus healthy nutrition: cultural gradients in Europe and the geography of baby food. GeoJournal 53:71-80

12. Bugge AB, Almas R (2006) Domestic dinner. Representations and practices of a proper meal among young suburban mothers. J Consumer Culture 6:203-228

13. Keys AB (1975) How to Eat Well and Stay Well the Mediterranean Way. Doubleday Publishing, Garden City

14. Brill JB (2009) The Mediterranean diet and your health. Am J Lifestyle Med 3:44

15. Gjonca A, Bobak M (1997) Albanian paradox, another example of protective effect of Mediterranean life style? Lancet 350: $1815-1817$

16. Corona G, Spencer JP, Dessi MA (2009) Extravirgin olive oil phenolics: absorption, metabolism, and biological activities in the GI tract. Toxicol Ind Health 225:285-293

17. Greco L, Musmarra F, Franzese C, Auricchio S (1998) Early childhood feeding practices in southern Italy: is the Mediterranean diet becoming obsolete? Study of 450 children aged 6-32 months in Campania, Italy. Acta Paediatr 87:250-256

18. Vidurrizaga-De Amezaga CA, Zulet MA, Marti A et al (2008) The Mediterranean food pattern: a good recipe for patients with the metabolic syndrome. Mediterr J Nutr Metab 1:2-14

19. Fusco M, Pezzi A, Benatti P et al (2010) Clinical features and colorectal cancer survival: an attempt to explain differences between two different Italian regions. Eur J Cancer 46:142-149

20. Guerra A, Feldl F, Koletzko B (2001) Fatty acid composition of plasma lipids in healthy Portuguese children: is the Mediterranean diet disappearing? Ann Nutr Metab 45:78-81

21. Polish Scientific Advisory Committee on Nutrition (2007) Healthy infant feeding guidelines. Polish J Pediatr 82:746-748

22. Przybylski R, Mag T (2002) Canola/rapeseed Oil. In: Gunstone FD (ed) Vegetable oils in food technology. Blackwell Publishing, Oxford

23. Gupta MK (2002) Sunflower Oil. In: Gunstone FD (ed) Vegetable Oils in Food Technology. Blackwell Publishing,

24. Lucas A, Quinlan P, Abrams S et al (1997) Randomised controlled trial of a synthetic milk formula for preterm infants. Arch Dis Child Fetal Neonatal Ed 77:F178-F184

25. Nor Aini L, Berger KG, Ong AS (1989) Evaluations of shortenings based on various palm oil products. J Sci Food Agric 46:481-493

26. Mace K, Shahkhalili Y, Aprikian O, Stan S (2006) Dietary fat and fat types as early determinants of childhood obesity: a reappraisal. Int J Obes (Lond) 30(Suppl 4):S50-S57
27. Chatzi L, Apostolaki G, Bibakis I et al (2007) Protective effect of fruits, vegetables and the Mediterranean diet on asthma and allergies among children in Crete. Thorax 62:677-683

28. Kim JL, Elfman L, Mi Y et al (2005) Current asthma and respiratory symptoms among pupils in relation to dietary factors and allergens in the school environment. Indoor Air 15:170-182

29. Alm JS, Schwartz J, Lilja G et al (1999) Atopy in children of families with an anthroposophic life style. Lancet 252:1485-1488

30. Andon BM, Anderson JW (2009) The oatmeal-cholesterol connection: 10 years later. Am J Lifestyle Med 2:51

31. Virtanen SM, Kaila M, Pekkanen J et al (2010) Early introduction of oats associated with decreased risk of persistent asthma and early introduction of fish with decreased risk of allergic rhinitis. Br J Nutr 103:266-273

32. Berti C, Riso P, Brusamolino A, Porrini M (2005) Effect on appetite control of minor cereal and pesudodereal products. Br J Nutr 94:850-858

33. Dunn EC (2004) Privatizing Poland: baby food, big business and the remaking of labor. Cornell University Press, Ithaca

34. Leonard S (1983) International health and transnational business: conflict or cooperation? Int Rev Adm Sci 49:259-268

35. Ahmed J (2007) Rheological, thermal and dielectric properties of pureed baby foods. Stewart Postharv Rev 5:2

36. Fox MK, Reidy K, Karwe V, Ziegler P (2006) Avarage portions of foods commonly eaten by infants and toddlers in the United States. J Am Diet Assoc 106:S66-S76

37. Ioannou S (2009) "Eating beans...that is a "no-no" for our times': young Cypriots' consumer meanings of 'healthy' and 'fast' food. Health Educ J 68:186-195

38. Sellen DW (2007) Evolution of infant and young child feeding: implications for contemporary public health. Annu Rev Nutr 27:123-148

39. Alonso AD (2008) Olive entrepreneurship in the southern hemisphere: the case of New Zealand. Int J Rural Manag 4:67-85

40. Fantoni L, Simoneau C (2003) European survey of contamination of homogenized baby food by epoxidized soybean oil migration from plasticized PVC gaskets. Food Addit Contam 20:1087-1096

41. Hakkinen SH, Karenlampi SO, Mykkanen HM, Torronen AR (2000) Influence of domestic processing and storage on flavonol contents in berries. J Agric Food Chem 48:2960-2965

42. Restani P, Fiocchi A, Restelli AR et al (1997) Effect of technological treatments on digestibility and allergenicity of meat-based baby foods. J Am Coll Nutr 16:376-382 